\title{
Capital Taxation May Survive in Open Economies
}

\author{
Michael Braulke \\ University of Osnabrück \\ and \\ Giacomo Corneo \\ Department of Economics, Free University of Berlin, Boltzmannstr. 20, 14195 \\ Berlin, Germany \\ E-mail: gcorneo@wiwiss.fu-berlin.de
}

\begin{abstract}
Why do capital taxes still exist in an integrated world economy? When capital is perfectly mobile across countries and labour is fixed, a source-based tax on capital both reduces and redistributes world income. In a simple general equilibrium model we show that under plausible circumstances there always exists a country that benefits from introducing such a tax. Countries that are richer in terms of human rather than financial capital tend to benefit from capital taxation. (c) 2004 Peking University Press
\end{abstract}

Key Words: International capital taxation; Redistribution; Incidence.

JEL Classification Number: $\mathrm{H} 2$

\section{INTRODUCTION}

It is often maintained that the survival of capital taxation in an integrated world economy is at odds with the theory of tax incidence, which has a tax on a completely mobile factor (like capital) to be eventually borne by the less mobile factors (like labour) if the country introducing the tax is small.

The underlying argument for the demise of capital taxes is simple enough. Consider a country too small to have an influence on world equilibrium prices, and assume that capital is the mobile factor and labour is the fixed one. The introduction of a source-based $\operatorname{tax} \tau$ on capital in such a country will then not affect the world equilibrium rate of return on capital, $r^{w}$. And as capital is assumed to be perfectly mobile across borders, investors in the country with the tax will have to realize the same net return they 
may obtain abroad. Hence their gross return must equal $r^{w}+\tau$, and the domestic market-clearing wage has to fall. This is interpreted to mean that the tax is borne by labour and that capital owners remain spared. While taxing labour would also reduce the net wage, it would not distort the decision to invest at home vs. abroad. Hence a labour income tax is thought to dominate a corporate income tax, even from the perspective of labour.

However, the prediction that source-based taxes on capital are not used is not in line with observation. Virtually all countries in the world tax the capital income earned by corporations located within their borders. ${ }^{1}$ The standard reaction of institutional policy advisors, like the IMF and the OECD, to this state of affairs has been to recommend national governments to cut their corporate taxes. Some scholars have instead tried to identify factors that might justify capital taxation in open economies, but are neglected by the standard model. Such factors include a country's market power in world capital markets, investors' home bias, and problems to enforce a tax on an individual's return to savings. ${ }^{2}$

The purpose of this paper is to revisit and generalize the general equilibrium model in Bradford (1978), and thereby to demonstrate that under plausible circumstances there always exists a country that benefits from introducing a capital tax. As Bradford showed, the predictions about tax incidence reported above are an artifact of partial-equilibrium analysis. In a general equilibrium model, the capital tax is borne by worldwide capital owners, and the workers in the country with the capital tax exactly lose what foreign workers gain.

We show that the domestic workers' loss in terms of wage income is always less than the tax revenue generated by the tax. Hence, the capital tax can be used for redistribution within the country, and using such a tax can raise domestic social welfare under some conditions. Moreover, situations exist in which all citizens in a country benefit from introducing a capital tax. This occurs, for instance, if the domestic distribution of factor endowments is egalitarian and the part of national human capital in world human capital is larger than the share of world financial capital owned by nationals.

In sum, both within-country and cross-country redistributive effects can suffice to explain the survival of capital taxation in spite of the integration of world capital markets.

\footnotetext{
${ }^{1}$ For an overview of current systems of international taxation, see e.g. Cnossen (2000). Recent evidence on the impact of company taxes on foreign direct investment is discussed by Hines (1999).

${ }^{2}$ See e g. Gordon and Hines (2002) and Slemrod (2004).
} 


\section{THE MODEL}

\subsection{Assumptions}

Consider the following extension of Bradford's (1978) two-factor model in which countries are allowed to have different shares in the world's labour. The world consists of countries $i=1,2, \ldots, I$ that produce a single output with an identical linear-homogeneous technology $F\left(K^{i}, L_{i}\right)$. Factor markets are competitive, so that factors earn their respective marginal product. Total world capital, denoted by $K=\sum_{i=1}^{I} K^{i}$, is perfectly mobile across borders. Labour is measured in skill units and is completely immobile. Let $L=\sum_{i=1}^{I} L_{i}$ denote the worldwide endowment of labour and $\lambda_{i}=L_{i} / L$ denote the share of country $i$ 's labour in total labour.

In the status-quo there is no taxation and the entire world is a laissezfaire economy. Then, country 1 introduces a small tax $\tau$ on capital invested within the country. The proceeds of taxation are uniformly redistributed to country 1's residents, denoted by $j=1,2, \ldots J$. The labour endowment of a country 1's resident is denoted by $l_{j}$, while his endowment of financial assets - representing claims on the capital used by firms - is denoted by $a_{j}$.

\section{2. $\quad$ Factor returns}

Given the linear homogeneity of the production functions we have the well-known identity $F\left(K^{i}, L_{i}\right)=L_{i} f\left(k^{i}\right)$ and the equally well-known relations $F_{K}\left(K^{i}, L_{i}\right)=f^{\prime}\left(k^{i}\right)$ and $F_{L}\left(K^{i}, L_{i}\right)=f\left(k^{i}\right)-k^{i} f^{\prime}\left(k^{i}\right)$. Thus, the marginal products of capital and labour only depend on the country's capital intensity $k^{i}$. Now, assume that country 1 introduces a source-based tax $\tau$ on capital. Since this factor is perfectly mobile by assumption, its net return must be equal in all countries irrespective of where it is invested. Hence,

$$
r^{w}(\tau)+\tau=f^{\prime}\left(k^{1}(\tau)\right)
$$

and

$$
r^{w}(\tau)=f^{\prime}\left(k^{i}(\tau)\right) \quad, \quad i=2, \ldots, I
$$

must hold. Differentiating (1) and (2) with respect to $\tau$ yields

$$
r_{\tau}^{w}(\tau)+1=f^{\prime \prime}\left(k^{1}(\tau)\right) K_{\tau}^{1}(\tau) / L_{1}
$$

and

$$
r_{\tau}^{w}(\tau)=f^{\prime \prime}\left(k^{i}(\tau)\right) K_{\tau}^{i}(\tau) / L_{i} \quad, \quad i=2, \ldots, I .
$$

Multiplying (3) by $\lambda_{1}=L_{1} / L$ and (4) by $\lambda_{i}=L_{i} / L$ and summing the results yields $r_{\tau}^{w}(\tau)+\lambda_{1}=\sum_{i} f^{\prime \prime}\left(k^{i}(\tau)\right) K_{\tau}^{i} / L$. Evaluating this expression at the point $\tau=0$ simplifies to 


$$
r_{\tau}^{w}(0)+\lambda_{1}=f^{\prime \prime}(k) \sum_{i} K_{\tau}^{i}(0) / L
$$

because at $\tau=0$ all countries still operate at identical capital intensities: $k^{i}(0)=k=K / L$. As a result,

$$
r_{\tau}^{w}(0)=-\lambda_{1},
$$

since the changes in the countries' capital stocks, $K_{\tau}^{i}$, must sum to zero.

Before we proceed to interpret this key result, it is useful to derive the changes in tax revenue, world capital income and world wage income first.

Differentiating the tax revenue $T(\tau)=\tau K^{1}(\tau)$ with respect to $\tau$ one has $T_{\tau}(\tau)=K^{1}(\tau)+\tau K_{\tau}^{1}(\tau)$, which gives

$$
T_{\tau}(0)=K^{1}(0) .
$$

For world capital income $C(\tau)=r^{w}(\tau) K$ one finds accordingly $C_{\tau}(\tau)=$ $r_{\tau}^{w}(\tau) K$ and

$$
C_{\tau}(0)=r_{\tau}^{w}(0) K=-\lambda_{1} K
$$

where use was made of (5). Since $\lambda_{1} K=L_{1} K / L=L_{1} k^{1}(0)=K^{1}(0)$, we can rewrite the effect on world capital income as

$$
C_{\tau}(0)=-K^{1}(0)
$$

For world wage income $W(\tau)=\sum_{i}\left[f\left(k^{i}(\tau)\right)-k^{i}(\tau) f^{\prime}\left(k^{i}(\tau)\right)\right] L_{i}$ we have

$$
W_{\tau}(\tau)=-\sum_{i} k^{i}(\tau) f^{\prime \prime}\left(k^{i}(\tau)\right) K_{\tau}^{i}(\tau)
$$

Evaluating this expression at $\tau=0$ yields

$$
W_{\tau}(0)=-k f^{\prime \prime}(k) \sum_{i} K_{\tau}^{i}(0)=0 .
$$

\subsection{National income}

Disposable income of a resident $j$ in country 1 amounts to

$$
y^{j}(\tau)=l_{j} \frac{W^{1}(\tau)}{L_{1}}+a_{j} r^{w}(\tau)+\frac{T(\tau)}{J} \quad, \quad j=1,2, \ldots, J,
$$

where $W^{1}(\tau)$ is the country's wage bill. The effect from taxing capital and distributing the proceeds is given by

$$
y_{\tau}^{j}(0)=l_{j} \frac{W_{\tau}^{1}(0)}{L_{1}}+a_{j} r_{\tau}^{w}(0)+\frac{T_{\tau}(0)}{J},
$$


where

$$
W_{\tau}^{1}(\tau)=-k^{1}(\tau) f^{\prime \prime}\left(k^{1}(\tau)\right) K_{\tau}^{1}(\tau) .
$$

By (3) and (5) one obtains

$$
W_{\tau}^{1}(0)=-\left(1-\lambda_{1}\right) K^{1}(0)
$$

Inserting equations (10), (5) and (6) into (9) yields

$$
y_{\tau}^{j}(0)=-l_{j}\left(1-\lambda_{1}\right) k-a_{j} \lambda_{1}+k \bar{l} \quad, \quad j=1,2, \ldots, J,
$$

where $\bar{l}=L_{1} / J$ denotes the average endowment of skill units in country 1 . It follows that individual $j$ benefits from the redistributive program if and only if $k \bar{l}>l_{j}\left(1-\lambda_{1}\right) k+a_{j} \lambda_{1}$ or

$$
\frac{l_{j}}{\bar{l}}\left(1-\lambda_{1}\right)+\frac{a_{j}}{\bar{a}} \alpha_{1}<1,
$$

where $\bar{a}=\sum_{j=1}^{J} a_{j} / J$ denotes average financial wealth in the country and $\alpha_{1}=\sum_{j=1}^{J} a_{j} / K$ is the share of world capital owned by domestic residents.

By (11) the effect of the tax on national income is given by

$$
\sum_{j=1}^{J} y_{\tau}^{j}(0)=\lambda_{1}\left(K^{1}(0)-\sum_{j=1}^{J} a_{j}\right) .
$$

Hence, the condition for national income to rise is

$$
\sum_{j=1}^{J} y_{\tau}^{j}(0)>0 \quad \Leftrightarrow \quad \lambda_{1}>\alpha_{1} .
$$

\subsection{Income inequality}

Consider the benchmark case where $l_{j} / \bar{l}=a_{j} / \bar{a}=\theta_{j}$ and the individuals are ordered in such a way that $\theta_{j}$ is weakly increasing in $j$. Disposable income then reads

$$
y^{j}(0)=\theta_{j}\left(\frac{W^{1}(0)}{J}+r^{w}(0) \bar{a}\right)+\frac{T(0)}{J} \quad, \quad j=1,2, \ldots, J .
$$

Denote the Lorenz curve of disposable income in country 1 as

$$
\mathcal{L}\left(\frac{h}{J}\right)=\frac{\sum_{j=1}^{h} y^{j}}{\sum_{j=1}^{J} y^{j}} \quad, \quad h=1,2, \ldots, J .
$$


The effect of the capital tax on the distribution of income in country 1 is

$$
\frac{\left.\partial \mathcal{L}(h / J)\right|_{\tau=0}}{\partial \tau} \geq 0 \Leftrightarrow \frac{\sum_{j=1}^{h} y_{\tau}^{j}(0)}{\sum_{j=1}^{h} y^{j}(0)} \geq \frac{\sum_{j=1}^{J} y_{\tau}^{j}(0)}{\sum_{j=1}^{J} y^{j}(0)}
$$

Since we may write $y_{\tau}^{j}(0)=k \bar{l}-\theta_{j}\left[\left(1-\lambda_{1}\right) k \bar{l}+\lambda_{1} \bar{a}\right]$, it is obvious that $y_{\tau}^{j}(0)$ decreases with $j$ while, according to $(14), y^{j}(0)$ increases with $j$. Therefore,

$$
\frac{\sum_{j=1}^{h} y_{\tau}^{j}(0)}{\sum_{j=1}^{h} y^{j}(0)} \quad, \quad h=1,2, \ldots, J
$$

is decreasing in $h$. In conjunction with (15), this implies that the capital tax shifts the Lorenz curve upwards unless $\theta_{j}$ is constant for all $j$.

\section{IMPLICATIONS}

1. Equation (5) says that the introduction of a tax on capital in country 1 reduces the world market rate of interest $r^{w}$ by exactly $\lambda_{1}$, its share in world capital ${ }^{3}$. If country 1 is small, the world interest rate will fall by correspondingly little or, in the borderline case $\lambda_{1} \rightarrow 0$, not at all.

2. The capital owners carry the full tax, as can be seen from (7) in conjunction with (6). Irrespective of how small country 1 and thus $\lambda_{1}$ is, world capital income declines by exactly the amount of the tax revenue. From a global point of view it is thus the capital owners who pay the entire tax.

3. From a purely national point of view the outcome is somewhat different. When looking at country 1 , equation (10) states that a share $1-\lambda_{1}$ of the tax has to be borne by country 1's wage earners through a fall of the domestic market-clearing wage rate.

4. From a global point of view, however, world wage income remains untouched. This is what (8) says, and that means that workers in the rest of the world gain exactly what the workers in country 1 loose. The reason is the outbound capital migration induced by the tax.

5 . From the point of view of country 1's residents, redistribution via a source-based tax increases consumption if condition (12) is met. This is the more likely when a resident's skill or financial wealth is low relative to the corresponding domestic average, and when he lives in a country that is comparatively rich in terms of human capital and poor in terms of financial wealth. If $l_{j} / \bar{l}=a_{j} / \bar{a}$ and $\lambda_{1}=\alpha_{1}$, the individual benefits from the program if and only if his market income is below domestic average.

\footnotetext{
${ }^{3}$ At $\tau=0$ all countries operate at an identical capital intensity. Hence, their share in world labour, measured in skill units, is also their share in world capital.
} 
6. Having a uniform social transfer financed by a source-based tax on capital may fuel domestic welfare even if the country with this program has an egalitarian income distribution. In case of $l_{j}=\bar{l}$ and $a_{j}=\bar{a}$ for all $j$, condition (12) shows that a Pareto-improvement occurs in country 1 if $\lambda_{1}>\alpha_{1}$, i.e. if nationals are relatively richer in terms of human rather than in terms of financial capital. The reason is the redistributive effect from the rest of the world.

7. An egalitarian world economy has $l_{j}=\bar{l}, a_{j}=\bar{a}$ and $\lambda_{1}=\alpha_{1}$. As implied by (12), in an egalitarian world economy no country would ever start using a tax on capital.

8. If $l_{j} / \bar{l}=a_{j} / \bar{a} \neq 1$ for all $j$, condition (15) shows that introducing the capital tax promotes equality in terms of Lorenz dominance. Assume that residents in country 1 are endowed with a common utility function, strictly increasing and concave in consumption. If $\lambda_{1} \geq \alpha_{1}$, average income does not decrease in the country - see condition (13). In this case, the theorem of Atkinson (1970) applies to show that social welfare in country 1 is raised by the tax on capital.

9. Consider an unequal world economy with the features of the point above and in which utilitarian national planners noncooperatively set sourcebased capital taxes. In any Nash-equilibrium of that game, capital taxes exist with strictly positive probability.

\section{CONCLUSION}

The survival of capital taxes in open economies can be explained within the standard neoclassical framework of competitive markets and rational actors. As implied by Bradford (1978), capitalists' grumbles about corporate taxes and other taxes on capital may simply be due to the fact that it is them who bear the burden of taxation. The current paper has shown that workers may also be acting in their own interest when they demand a capital tax. And if national governments are benevolent, there will typically be at least one of them that should use a capital tax.

\section{REFERENCES}

Atkinson, A., 1970, On the measurement of inequality. Journal of Economic Theory 2, 244-63.

Bradford, D., 1978, Factor prices may be constant but factor returns are not. Economics Letters 1, 199-203.

Cnossen, S., ed., 2000, Taxing Capital Income in the European Union (Oxford University Press, New York)

Gordon, R.H. and J.R. Hines Jr., 2002, International taxation. NBER Working Paper 8854 . 
Hines Jr., J.R., 1999, Lessons from behavioral responses to international taxation. National Tax Journal 52, 305-322.

Slemrod, J., 2004, Are corporate tax rates, or countries, converging? Journal of Public Economics 88, 1169-86. 